\title{
Shape-selective $n$-alkane hydroconversion at exterior zeolite surfaces
}

\author{
Theo L.M. Maesen ${ }^{\mathrm{a}, *}$, Rajamani Krishna ${ }^{\mathrm{b}}$, Jasper M. van Baten ${ }^{\mathrm{b}}$, Berend Smit $^{\mathrm{b}, \mathrm{c}, \mathrm{d}}$, Sofia Calero ${ }^{\mathrm{e}}$, \\ Juan Manuel Castillo Sanchez ${ }^{\mathrm{c}}$ \\ a Chevron, Energy Technology Company, 100 Chevron Way, Richmond, CA 94802-0627, USA \\ b Van't Hoff Institute for Molecular Sciences, University of Amsterdam, Nieuwe Achtergracht 166, 1018 WV, Amsterdam, The Netherlands \\ ' Centre Europeén de Calcul Atomique et Moleculaire (CECAM), Ecole Normale Supérieure (ENS) 46, Allée d'Italie, 69007 Lyon, France \\ ${ }^{\mathrm{d}}$ Department of Chemical Engineering, University of California at Berkeley, 101B Gilman Hall \#1462, Berkeley, CA 94720 , USA \\ e Department of Experimental Science, University Pablo de Olavide, Ctra de Utrera, Km. 1, 41013 Seville, Spain
}

Received 8 January 2008; revised 1 March 2008; accepted 3 March 2008

Available online 11 April 2008

\begin{abstract}
A critical review of the adsorption and catalysis of $n$ - and methylalkanes demonstrates that the interior surface of TON-and MTT-type zeolites dominates both adsorption and catalysis, and that the contribution from the exterior surface is negligible. For both $n$ - and methylalkane isomers, the experimental Henry constants at the interior TON-type zeolite surface are more than an order of magnitude greater than those at the exterior surface. Molecular simulations on exclusively interior TON-type silica surface reproduce the adsorption isotherms of $n$ - and methylalkane isomers remarkably well and suggest that even an isomer as bulky as 2,3-dimethylpentane could have access to the interior TON-type zeolite surface. Only the reference state used in solution thermodynamics affords an equitable comparison between internal and external surface thermodynamics. It indicates that methylalkanes adsorb in a structured fashion at the exterior TON-type zeolite surface when the interior surface is inaccessible. But the entropic penalty for this organized exterior surface "pore mouth" or "key-lock" adsorption is high, so that methylalkanes prefer adsorption at the interior surface when it is accessible. We speculate that CHA- and ERI-type sieves exhibit exterior surface catalysis in long $n$-alkane conversion, but the database remains too small to allow investigation of the full potential of shape selectivity in exterior zeolite surface catalysis.
\end{abstract}

(C) 2008 Elsevier Inc. All rights reserved.

Keywords: Ostwald coefficient; Adsorption thermodynamics; Solution thermodynamics; TON-, MTT-, CHA-, ERI-type zeolites; Alkane hydroconversion; Shape selectivity; Exterior zeolite surface catalysis

\section{Introduction}

Zeolites continue to play a major role in industrial catalysis, because they contain extremely well-defined pores of molecular dimensions that can process molecules shape selectively [1]. In its most rudimentary definition, processing molecules shape selectively means that zeolites process only those molecules that have full access to their interior surface $[1,2]$. When the term "shape selectivity" was coined, it was noted that the interior surface of zeolites does not process all molecules, leaving some molecules to be processed at the exterior surface [2]. Process-

\footnotetext{
* Corresponding author.

E-mail address: tmaesen@ chevron.com (T.L.M. Maesen).
}

ing at the exterior surface is generally considered undesirable, because the exterior surface lacks the structural definition to impart shape selectivity [2-5]. Nevertheless, it is often postulated that the exterior zeolite surface may be sufficiently structured to afford shape-selective conversion of molecules that are too large [4-17] or that diffuse too sluggishly [18-21] to gain full access to the interior surface.

Shape-selective conversion at the exterior zeolite surface remains incompletely understood and a subject of debate [22-28]. To the extent that this debate has been settled, current opinion holds that no shape-selective catalysis occurs at the exterior surface of MFI-type zeolites, and that all shape selectivity occurs at the interior surface [22,23]. Catalysis at the exterior surface of MWW-type zeolites [19-21] occurs through a mechanism and 
with selectivity similar to traditional Friedel-Crafts catalysis $[29,30]$, which implies that it is not a case of shape selectivity. Only the shape-selective hydroconversion of long $n$-alkanes at the exterior surface of TON-, MTT-, ERI-, and CHA-type zeolites [4,6-17] remain under discussion. In the present paper, we critically review exterior surface catalysis and suggest that TON- and MTT-type zeolites do not exhibit shape-selective exterior surface catalysis, whereas ERI- and CHA-type molecular sieves do exhibit exterior surface catalysis that might be shapeselective.

Tubular-pore zeolites (e.g., TON-, MTT-, MTW-, GON-, and ZSM-48-type zeolites) are of industrial interest because they absorb and hydroisomerize long linear alkanes (wax), effectively turning them into high-value base oil [31-36]. Catalysts based on tubular-pore zeolites have replaced catalysts based on intersecting-pore MFI-type zeolites, which absorb and hydrocrack the long linear alkanes out of the base oil fraction into less-valuable products [32-35]. The higher hydroisomerization selectivity of the nonintersecting tubular-pore zeolites and the higher hydrocracking selectivity of the intersecting-pore MFItype zeolite result from the way in which these zeolites process hydrocracking precursors. Hydrocracking precursors are alkanes with proximate methyl groups [37-39]. Intersecting-pore MFI-type zeolites enhance formation of alkanes with proximate methyl groups (and thereby the extent of hydrocracking), because the MFI-type intersections afford a snug fit with these precursors, thereby decreasing the Gibbs free energy of formation of these hydrocracking precursors [40,41]. Tubular-pore zeolites impede the formation of alkanes with proximate methyl groups and thus impede hydrocracking in favor of hydroisomerization [4-14,24-27,42-44]. How the nonintersecting tubular TON- and MTT-type pores impede formation of alkanes with proximate methyl groups remains incompletely understood. One possible explanation is that they impede formation of alkanes with proximate methyl groups, because these alkanes fit poorly inside the narrow TON-, MTT-, MTW-, or ZSM48-type pores [24-27,41-45]; another possibility is that they impede formation of alkanes with proximate methyl groups, because not even an alkane with a single methyl group fits inside TON- or MTT-type pores [4-15].

The hypothesis that no methylalkane fits inside TON-type zeolite pores led to the postulation of "pore mouth" and "keylock" catalysis-reaction schemes all occurring in a layer of alkane isomers adsorbed epitaxially at the exterior TONand MTT-type zeolite crystals [4-15]. Originally, a molecular graphics assessment formed the basis for the key hypothesis that methylalkanes are too large to fully enter TONtype pores [6]. Subsequent molecular simulations unanimously agreed that the original molecular graphics assessment had significantly overestimated the molecular size of methylalkanes, and that methylalkanes should fit inside a TON- or MTT-type pore (see Fig. 1) [24-27]. However, these computational studies assumed that the experimental adsorption studies involve zeolites that reach full thermodynamic equilibrium. One could argue that kinetic barriers prevent equilibration on the time scale of the experiments. Additional experimental studies allegedly corroborated the original hypothesis that methylalkanes
TON

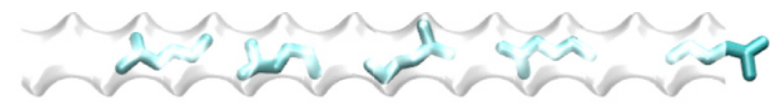

MTT

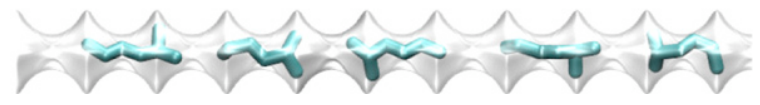

Fig. 1. Stick model images of 2-methylhexane molecules at their disputed positions inside TON- (top) and MTT- (bottom) type zeolites. The shaded areas at the top represent TON-type channels, which consist of linear arrays of 0.51-nm-wide windows providing access to $0.57-\mathrm{nm}$ cages (top). The shaded areas at the bottom represent MTT-type channels, which consist of linear arrays of 0.50-nm windows providing access to 0.61-nm cages (bottom) [96].

do not fit $[5,9,10]$. In this paper, we reanalyze these additional experimental data and demonstrate that these data refute, rather than corroborate, the hypothesis that no branched alkane has full access to the interior surface of TON- and MTT-type pores. This analysis uses thermodynamic reference states customarily used in solution thermodynamics [46-49], catalysis [23, 50-54], chromatography [8-10,55], and molecular simulations [56,57].

In principle, the most straightforward way of evaluating whether a methylalkane (or any adsorbate) prefers adsorption at the exterior or at the interior surface is to quantify and compare its Gibbs free energies of adsorption at the respective surfaces. The adsorbate will prefer adsorption at the surface with the lowest (i.e., most negative) free energy of adsorption. Unfortunately, there is no general agreement on how to define (and quantify) the entropy term in the Gibbs free energy of adsorption [47,58]; therefore, we start by comparing the Henry coefficients determined for alkanes having access only to the exterior TON-type zeolite surface and for alkanes having access to both the interior and exterior surfaces. Furthermore, we compare adsorption in the intermediate (i.e., liquid-phase) pressure range, and we use molecular simulations to evaluate the high-pressure range required to reach alkane saturation loading. We then propose a definition for the link between Henry coefficient and adsorption entropy and use this definition in a more detailed thermodynamic analysis of the adsorption at the interior and exterior TON-type zeolite surfaces. This affords extension of the conclusions reached for the alkane adsorption on TON-type zeolites to the alkane adsorption on MTT-type zeolites. Finally, we discuss how the conclusions based on an improved understanding of $n$-alkane adsorption affect our understanding of $n$-alkane hydroconversion on TON-, MTT-, and CHA-type zeolites.

\section{Molecular simulation methods}

The configurational-bias Monte Carlo (CBMC) technique affords efficient calculation of the thermodynamic properties and adsorption isotherms of hydrocarbons in microporous silica structures $[59,60]$. In the CBMC scheme, the molecules are grown bead-by-bead, with the growth biased toward energetically more favorable conformations, thus avoiding overlaps with the zeolite. This results in a sampling scheme that is orders of magnitude more efficient than traditional Monte Carlo 
schemes, in which entire molecules are inserted at once, generating a high percentage of unlikely or impossible configurations in the process.

Our CBMC simulation model uses single interaction centers (i.e., united atoms) to represent the $\mathrm{CH}_{3}, \mathrm{CH}_{2}, \mathrm{CH}$, and $\mathrm{C}$ groups in the linear and branched alkanes. The bonded interactions include bond-bending and torsion potentials. Dispersive interactions with the oxygen atoms of the silica structure are assumed to dominate the silica-alkane interactions. The zeolite is modeled as a rigid crystal $[59,60]$ comprising exclusively $\mathrm{SiO}_{2}$, so as to make the calculation of alkane-zeolite interactions more efficient using special interpolation techniques [59-61]. The sizes of the molecules and the energy parameters have been fitted to faithfully reproduce the experimentally determined isotherms (particularly the inflection points) on MFItype zeolites over a wide range of pressures and temperatures $[59,60]$. The resultant force field reproduces the Henry coefficients, enthalpies and entropies of adsorption, and maximum loading extremely well $[59,60]$. The same force field also reproduces these parameters remarkably well for microporous silica topologies other than the MFI type [62]. More details about the simulation method and the force fields are described elsewhere $[59,60]$.

\section{Discussion}

\subsection{Interior and exterior surface adsorption at TON-type zeolites in the Henry regime}

When evaluating whether branched alkanes adsorb only at the exterior surface of TON-type zeolite crystals, elegant adsorption experiments were conducted on TON-type zeolite crystals that had virtually no accessible interior surface [10]. This was accomplished by omitting the calcination step after the TON-type zeolite synthesis, so that the interior surface remained clogged up with void filler $[10,44]$. According to nitrogen adsorption, the void filler blocks access to the interior surface very effectively; the micropore volume of these filled, noncalcined TON-type pores is a mere $0.1 \%$ of the micropore volume of the empty, calcined TON-type pores [10]. Thus, it is very reasonable to assume that the Henry coefficient of the filled, noncalcined TON-type pores truly represents the adsorption at the exterior crystal surface only, whereas the Henry coefficient on the empty, calcined TON-type pores represents combined adsorption at both exterior and interior crystal surfaces. The importance of this supposition lies in the fact that the Henry coefficients are an experimental probe to assess the surface contribution to the adsorption. Early analyses of these Henry coefficients $[5,8,10]$ concluded that only the $n$-alkanes, not the methylalkanes, enter the TON-type pores. Later studies refined this conclusion and argued that methylalkanes do enter the TON-type pores, but only after the methylalkanes have reached sufficiently high pressure $[9,11]$. However, the earlier conclusions were based on an interpretation of the experimental Henry coefficients that implicitly assumed that methylalkanes have access only to specific (pore mouth) sites at the exterior surface and that $n$-alkanes have access to the internal surface
Table 1

Henry constants of $n$-alkanes and 2- and 3-methylalkanes exposed to both the interior and the exterior TON-type zeolite crystal surface, $K_{\mathrm{H}}$ total $(\mathrm{mol} / \mathrm{kg} \mathrm{Pa})$, or to only the exterior crystal surface, $K_{\mathrm{H}}$ exterior only $(\mathrm{mol} / \mathrm{kg} \mathrm{Pa})$ as determined by Ocakoglu et al. [10] at $473 \mathrm{~K}$. The exterior surface contribution to the total Henry coefficient, $\%$ exterior, is defined as $100 \% \times$ $K_{\mathrm{H} \text { exterior only }} / K_{\mathrm{H} \text { total }}$

\begin{tabular}{llll}
\hline & $\begin{array}{l}K_{\mathrm{H} \text { total }} \\
(\mathrm{mol} / \mathrm{kg} \mathrm{Pa})\end{array}$ & $\begin{array}{l}K_{\mathrm{H} \text { exterior only }} \\
(\mathrm{mol} / \mathrm{kg} \mathrm{Pa})\end{array}$ & \% exterior \\
\hline$n-\mathrm{C}_{5}$ & $2.70 \times 10^{-5}$ & $5.30 \times 10^{-7}$ & 2.0 \\
$n-\mathrm{C}_{6}$ & $8.82 \times 10^{-5 \mathrm{a}}$ & $1.10 \times 10^{-6}$ & 1.2 \\
$n-\mathrm{C}_{7}$ & $2.90 \times 10^{-4}$ & $2.60 \times 10^{-6}$ & 0.9 \\
$n-\mathrm{C}_{8}$ & $9.65 \times 10^{-4 \mathrm{a}}$ & $7.30 \times 10^{-6}$ & 0.8 \\
$n-\mathrm{C}_{9}$ & $3.45 \times 10^{-3 \mathrm{a}}$ & $2.00 \times 10^{-5}$ & 0.6 \\
$2-\mathrm{Me}-\mathrm{C}_{4}$ & $4.30 \times 10^{-6}$ & $2.41 \times 10^{-7 \mathrm{a}}$ & 5.6 \\
$2-\mathrm{Me}-\mathrm{C}_{5}$ & $1.20 \times 10^{-5}$ & $5.71 \times 10^{-7 \mathrm{a}}$ & 4.8 \\
$2-\mathrm{Me}-\mathrm{C}_{6}$ & $4.10 \times 10^{-5}$ & $1.40 \times 10^{-6}$ & 3.4 \\
$2-\mathrm{Me}-\mathrm{C}_{7}$ & $1.00 \times 10^{-4}$ & $3.20 \times 10^{-6}$ & 3.2 \\
$2-\mathrm{Me}-\mathrm{C}_{8}$ & $2.90 \times 10^{-4}$ & $8.00 \times 10^{-6}$ & 2.8 \\
$3-\mathrm{Me}-\mathrm{C}_{5}$ & $8.80 \times 10^{-6}$ & $4.77 \times 10^{-7 \mathrm{a}}$ & 5.4 \\
$3-\mathrm{Me}-\mathrm{C}_{6}$ & $2.70 \times 10^{-5}$ & $1.10 \times 10^{-6}$ & 4.1 \\
$3-\mathrm{Me}-\mathrm{C}_{7}$ & $8.20 \times 10^{-5}$ & $3.40 \times 10^{-6}$ & 4.1 \\
$3-\mathrm{Me}-\mathrm{C}_{8}$ & $2.70 \times 10^{-4}$ & $9.70 \times 10^{-6}$ & 3.6 \\
\hline${ }^{2}$ & &
\end{tabular}

a Obtained through interpolation as suggested by values in Ref. [10].

and will adsorb there unless barred from doing so. Here we introduce some solution thermodynamic relations that allow interpretation of the experimental data without the need for these assumptions.

Applying this alternative approach, we reach markedly different conclusions. Comparison of the Henry coefficients on calcined and noncalcined TON-type zeolites indicates that the exterior surface contributes $1-2 \%$ of the overall $n$-alkane adsorption and $3-6 \%$ of the methylalkane adsorption on TONtype zeolites (Table 1). Under this approach, these Henry coefficients indicate that the interior surface dominates the adsorption of both $n$-alkanes and methylalkanes, being responsible for $>94 \%$ of the adsorption of both of these alkanes (Table 1).

\subsection{Adsorption at TON-type zeolites at intermediate pressure}

By extrapolating adsorption isotherms measured up to an intermediate pressure range $(<40 \mathrm{kPa}$ at $506 \mathrm{~K})$, it has been argued that methylalkanes exhibit a dramatically lower saturation loading compared with the full accessible micropore volume [5]. This low saturation loading supports the exclusive access of methylalkanes to the low exterior surface area and not to the high interior surface area. Molecular simulations reproduce these methylalkane adsorption isotherms remarkably well (Figs. 2A and 2B), even though the idealized TON-type silica adsorbent used in molecular simulations exhibits no exterior surface. This finding strongly suggests that the interior (and not the exterior) surface dominates the adsorption isotherms of methylalkanes in the intermediate pressure range. Moreover, molecular simulations afford evaluation of the isotherms at the high-pressure range (Figs. 2A and 2B). The full isotherms indicate that $n$-heptane and 2-methylhexane reach virtually the same saturation loading $\left(q_{\text {sat }}=0.55-0.56 \mathrm{~mol} / \mathrm{kg}\right)$, which cor- 


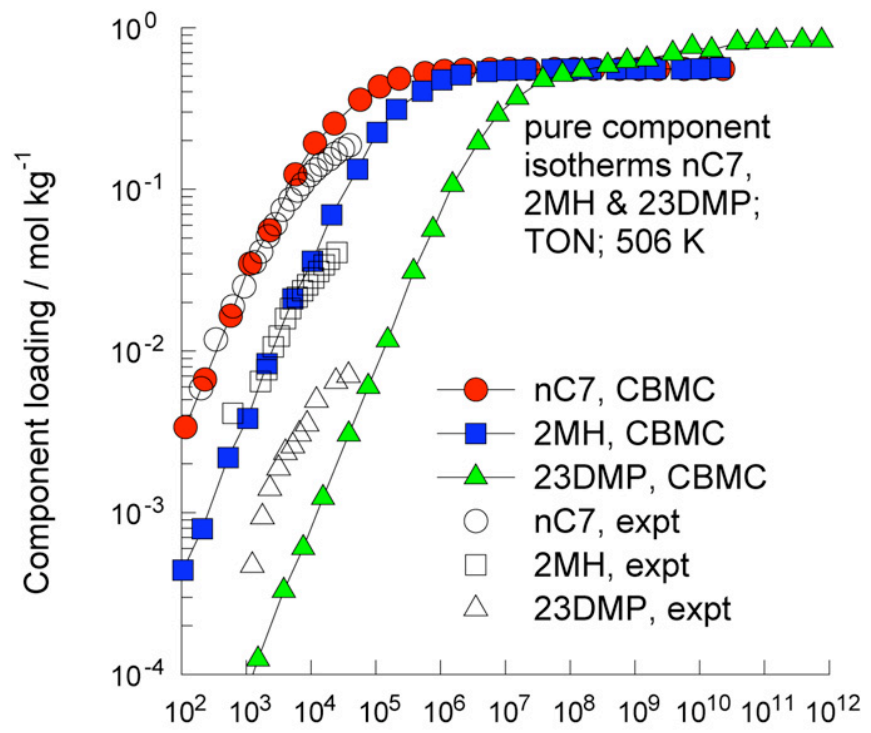

Bulk gas phase fugacity / $\mathrm{Pa}$

(A)

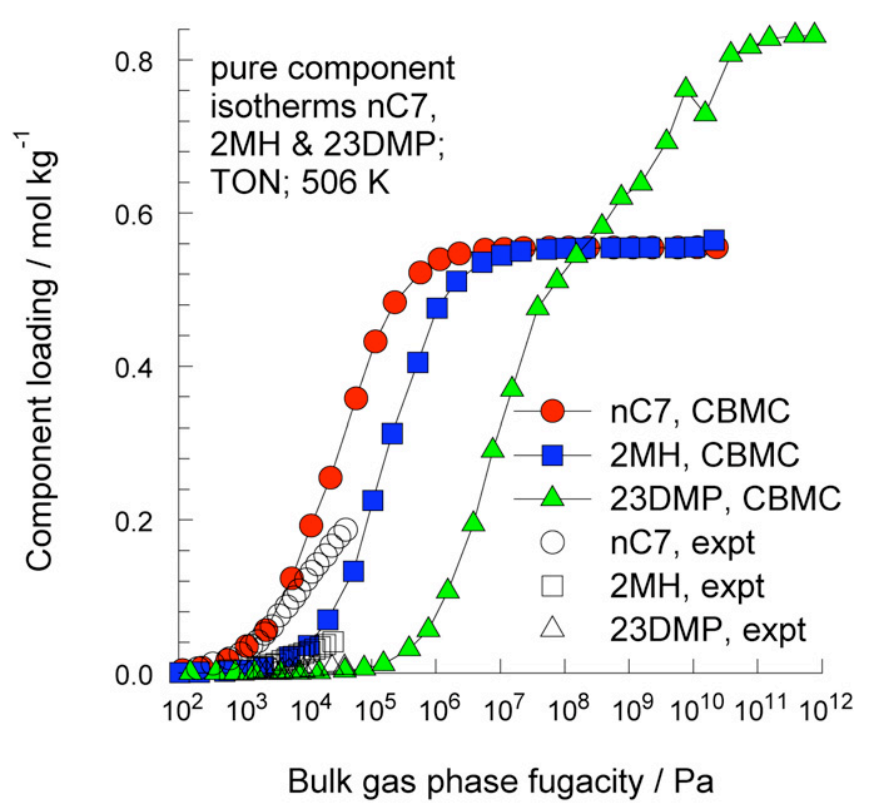

(B)

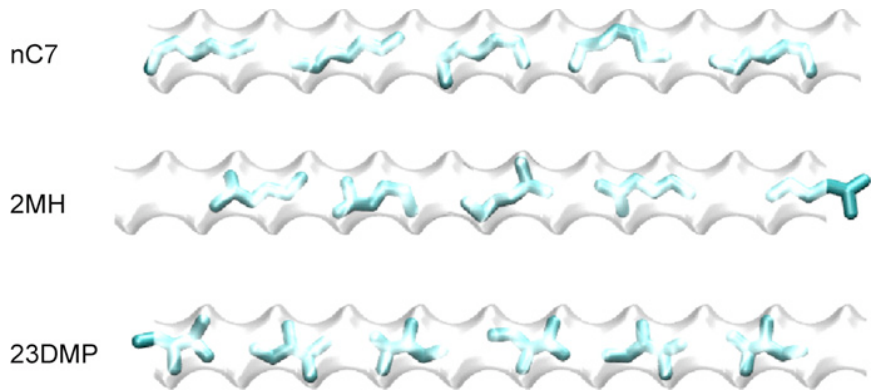

(C)

Fig. 2. (A) A comparison of the isotherms for $n$-heptane $(\boldsymbol{\bullet}, \bigcirc), 2$-methylhexane $(\boldsymbol{\square}, \square)$, and 2,3-dimethylpentane $(\boldsymbol{\Delta}, \triangle)$ adsorption on TON-type zeolites at $506 \mathrm{~K}$ as Denayer et al. obtained experimentally (open symbols [5]) and as obtained through molecular simulations (closed symbols). The fit between experimental and simulation results is excellent at low loading and pressure, for $n$-heptane and 2-methylhexane suggesting that the experimental values represent true equilibria and that the intrusion of kinetic effects is minimal. At higher loading experimental and simulation results diverge slightly, suggesting the intrusion of kinetic effects. For 2,3-dimethylpentane these conclusions are less clear. (B) A semi-logarithmic plot of the isotherms as shown in (A). It emphasizes that none of the experimental isotherms approach their saturation pressure, even though the isotherm as originally published (with a linear scale for both axes [5]) would suggest otherwise. $n$-Heptane $(\bullet, \bigcirc)$ reaches a similar saturation loading as 2-methylhexane $(\boldsymbol{\square}, \square)$, because both have a similar effective length at high pressure (C). 2,3-Dimethylpentane $(\boldsymbol{\Delta}, \triangle)$ reaches a significantly higher saturation loading, because it is significantly shorter than the linear or methylalkanes $(\mathrm{C})$. (C) Snapshots of $n$-heptane (nC7, top), 2-methylhexane (2MH, middle) and 2,3-dimethylpentane (23DMP, bottom), illustrating that the linear and mono-methylalkanes have a much larger "footprint" than the dimethylalkane, and-therefore-reach a lower saturation loading in TON-type zeolites at $506 \mathrm{~K}$.

responds to an accessible micropore volume $\left(V_{\mathrm{p}}=0.08 \mathrm{~mL} / \mathrm{g}\right)$ if the adsorbed phase is assumed to achieve liquid-phase density. This accessible micropore volume is in excellent agreement with experimental results $[10,11]$, further corroborating that the interior surface can accommodate both linear and methylalkane isomers at experimentally relevant pressures.

Molecular simulations underestimate the experimentally determined adsorption of 2,3-dimethylpentane (Figs. 2A and 2B), possibly suggesting a more significant contribution of the exterior surface to the experimental data. Clearly, 2,3-dimethylpentane requires a markedly higher pressure to access the interior TON-type zeolite surface compared with $n$-heptane or 2-methylhexane, due to its tighter fit inside the TON-type pores (Fig. 2C). At these higher pressures, 2,3-dimethylpentane reaches a significantly higher saturation loading than the monomethyl and linear isomers, higher than would be expected if all three isomer types adsorbed at their respective (similar) liquid-phase densities. This higher saturation loading of 2,3-dimethylpentane is due to its markedly smaller footprint (Fig. 2C). Higher saturation loadings due to smaller footprints can be exploited to separate alkane isomers with onedimensional zeolites [63]. Although the access of 2,3-dimethylpentane to the interior TON-type zeolite surface is difficult, the comparatively easy access of mono-methylalkanes is in stark contrast to the conclusions reached in papers reporting the experimental data [8-10]. However, subsequent papers reporting experimental data concluded that mono-methylalkanes and 2,3-dimethyl-butane and -pentane have access to the interior TON-type zeolite surface given sufficiently high pressure $[9,11]$. Implicitly, these authors suggested that the exterior surface dominates adsorption at low pressure whereas the interior surface dominates adsorption at high pressure. Molecular sim- 
Table 2

A comparison of experimental, $L_{\exp }(\mathrm{mol} / \mathrm{kg})$, as reported by Denayer et al. [9,11], and of simulated alkane loadings, $L_{\mathrm{sim}}(\mathrm{mol} / \mathrm{kg})$, at their respective alkane vapor pressure at $298 \mathrm{~K}$. Both TON- and MTT-type zeolites are considered. The alkane vapor pressures at $298 \mathrm{~K}$ were determined through interpolation of tabulated data [94]. Please note that for 2,3-dimethylpentane (23-DM-C5) the vapor pressure is well below the pressure required to saturate the pores (cf. Figs. 2A and 2B)

\begin{tabular}{|c|c|c|c|c|c|}
\hline & \multirow{2}{*}{$\begin{array}{l}\frac{298 \mathrm{~K}}{p} \\
(\mathrm{kPa})\end{array}$} & \multicolumn{2}{|l|}{ TON } & \multicolumn{2}{|l|}{ MTT } \\
\hline & & $\begin{array}{l}L_{\exp } \\
(\mathrm{mol} / \mathrm{kg})\end{array}$ & $\begin{array}{l}L_{\operatorname{sim}} \\
(\mathrm{mol} / \mathrm{kg})\end{array}$ & $\begin{array}{l}L_{\exp } \\
(\mathrm{mol} / \mathrm{kg})\end{array}$ & $\begin{array}{l}L_{\mathrm{sim}} \\
(\mathrm{mol} / \mathrm{kg})\end{array}$ \\
\hline$n$-C5 & 57.09 & 0.60 & 0.83 & n.p. ${ }^{a}$ & 0.57 \\
\hline$n$-C6 & 17.60 & 0.54 & 0.61 & 0.44 & 0.55 \\
\hline$n-\mathrm{C} 7$ & 5.33 & 0.47 & 0.55 & n.p. & 0.55 \\
\hline$n-\mathrm{C} 8$ & 1.47 & 0.43 & 0.55 & n.p. & 0.55 \\
\hline $2 \mathrm{Me}-\mathrm{C} 4$ & 77.01 & 0.44 & 0.83 & n.p. & 0.72 \\
\hline 2Me-C5 & 26.87 & 0.36 & 0.81 & 0.00 & 0.54 \\
\hline $3 \mathrm{Me}-\mathrm{C} 5$ & 25.32 & 0.34 & 0.82 & 0.00 & 0.49 \\
\hline 23-DM-C4 & 31.26 & 0.08 & 0.83 & n.p. & 0.01 \\
\hline 23-DM-C5 & 9.16 & 0.05 & 0.56 & n.p. & 0.00 \\
\hline
\end{tabular}

a n.p.: not published in Refs. [9,11].

ulations indicate that the interior surface dominates the adsorption at any pressure.

\subsection{Adsorption at TON-type zeolites at high pressure}

High-pressure adsorption data on TON-type zeolites were only reported at room temperature $[9,11]$. Assuming Langmuirtype adsorption and a liquid-phase saturation loading allows estimation of the corresponding Henry coefficient at room temperature $(298 \mathrm{~K})$ for the various alkane isomers. This estimated Henry coefficient turns out to be of similar magnitude as those reported for $473 \mathrm{~K}$, two orders of magnitude lower than the room temperature Henry coefficients that would be expected based on extrapolation of the high-temperature Henry coefficients (reported at $473 \mathrm{~K}$ and above [5]) to $298 \mathrm{~K}$ (see Supplementary material, A). Molecular simulations indicate that the reason for the reported low alkane loadings - and correspondingly low estimated Henry coefficients-is that all of the reported experimental loadings are below their (simulated) equilibrium values at $298 \mathrm{~K}$ (Table 2). This implies that kinetic effects interfere with all of the loadings reported at $298 \mathrm{~K}$ and that, for example, the lower diffusion rates of vicinal di-methyland mono-methylalkanes compared with $n$-alkanes contribute significantly to their lower loadings at $298 \mathrm{~K}[9,11]$. Nonetheless, these 298-K loadings led to the conclusion that the interior TON-type zeolite surface contributes significantly to the adsorption of mono-methyl and vicinal di-methylalkanes at high pressure, but not at low or intermediate pressures [9,11]. The postulated pressure dependence of the contribution of the exterior TON-type zeolite surface to methyl alkane adsorption is based largely on thermodynamic considerations and provides the incentive for a more detailed thermodynamic analysis.

\subsection{Thermodynamics of adsorption}

Adsorption thermodynamics is a part of classical thermodynamics in which there still is some debate. Contributing to the poor agreement on how best to describe the thermodynamics of adsorption is the fact that surface thermodynamics played such a dominant role for most of the latter half of the twentieth century [64-66]. Characteristically, surface thermodynamics introduces a concept called "spreading pressure" as the two-dimensional adsorbed-phase analogue of gas-phase pressure. Surface thermodynamics became extremely popular some 40 years ago, when the advent of nitrogen porosimetry and BET theory seemed to afford the full development of ideas that go back to Josiah Willard Gibbs. With recognition of the extreme limitations of the BET theory when applied to porous adsorbents [67], the popularity of BET theory and surface thermodynamics waned [64-66]. Some excellent papers have provided more detail on the need to move beyond surface thermodynamics [64-66] in search of, for example, a link between the Henry coefficient and adsorption enthalpy, $\Delta H_{\mathrm{ads}}(\mathrm{J} / \mathrm{mol})$, and especially adsorption entropy, $\Delta S_{\text {ads }}(\mathrm{J} / \mathrm{mol} \mathrm{K})$.

Nowadays, the Van't Hoff equation

$\frac{\mathrm{d} \ln K_{\mathrm{H}}}{\mathrm{d} T}=\frac{\Delta H_{\mathrm{ads}}}{R T^{2}}$

appears to be a cornerstone to the link between the Henry coefficient and adsorption enthalpy. In this equation, $T(\mathrm{~K})$ is the absolute temperature, and $R(=8.3144 \mathrm{~J} / \mathrm{mol} \mathrm{K})$ is the gas constant. The Van't Hoff equation is customarily used to determine the adsorption enthalpy from the slope of a plot of $\ln K_{\mathrm{H}}$ versus $1 / T$. Integration of Eq. (1) yields the familiar

$K_{\mathrm{H}}=K_{\mathrm{H}_{0}} \exp \left[-\frac{\Delta H_{\mathrm{ads}}}{R T}\right]$,

where $K_{\mathrm{H}_{0}}(\mathrm{~mol} / \mathrm{kg} \mathrm{Pa})$ is an integration constant. Whereas Eqs. (1) and (2) are generally agreed-upon relationships between the Henry coefficient and the adsorption enthalpy, there is no such clear agreement on how exactly the Henry coefficient relates to the adsorption entropy and, by extension, the Gibbs free energy of adsorption.

The root cause of the disagreement on how best to relate Henry coefficient and free energy is that there is no generally accepted standard adsorbed state. Typically, such a standard state is defined by

$\Delta Z_{\mathrm{ads}}=-R T \ln \left(K_{\mathrm{H}} \frac{p^{0}}{q^{0}}\right)$,

where $p^{0}(\mathrm{~Pa})$ is an arbitrary reference pressure and $q^{0}$ $(\mathrm{mol} / \mathrm{kg})$ is an arbitrary reference loading, so that the choice for $p^{0} / q^{0}(\mathrm{~Pa} \mathrm{~kg} / \mathrm{mol})$ defines a standard state [47]. $\Delta Z_{\text {ads }}(\mathrm{J} / \mathrm{mol})$ is either the Helmholtz free energy, $\Delta A_{\text {ads }}(\mathrm{J} / \mathrm{mol})$, or the Gibbs free energy of adsorption, $\Delta G_{\text {ads }}(\mathrm{J} / \mathrm{mol})$, depending on the choice for reference pressure $p^{0}$ (see Supplementary material, $\mathrm{B}$ and C). Usually any choice of a standard state is deemed acceptable as long as it is used consistently $[47,58]$ and as long as $K_{\mathrm{H}} p^{0} / q^{0}$ is dimensionless. In what follows, we illustrate that only a single reference state out of those currently in vogue affords the consistent comparison of internal and external surface adsorption.

Current approaches to defining a reference state include the following: 
- Use fixed values $p^{0} / q^{0}=P^{0} / Q^{0}[10]$

- Follow solution thermodynamics [46-48];

- Consider a pore-filling approach [47];

- Apply a specific isotherm, such as the Langmuir isotherm [47,68-77].

The first approach defines the standard entropy and the Gibbs free energy of adsorption $(\Delta Z=\Delta G$, in Eq. (3)) by defining arbitrarily chosen fixed values for the reference states. For example, the study cited earlier on the adsorption of alkanes on TON-type zeolites [10] used a fixed pressure, $p^{0}=$ $100 \mathrm{kPa}$, and an arbitrary low loading, $q_{0}(\mathrm{~mol} / \mathrm{kg})$, equivalent to half the estimated acid site density; however, it used $q^{0}=$ $1.7 \times 10^{-4} \mathrm{~mol} / \mathrm{kg}$ as a reference loading for $n$-alkanes that had access only to the exterior surface and $q^{0}=0.27 \mathrm{~mol} / \mathrm{kg}$ as a reference loading for $n$-alkanes that had access to both exterior and interior surfaces. For methylalkanes, it used $q^{0}=$ $1.7 \times 10^{-4} \mathrm{~mol} / \mathrm{kg}$ irrespective of which surfaces are accessible [10]. Clearly, the underlying assumption is that these different reference states do not affect the thermodynamic analysis.

The second approach is based on solution thermodynamics. It has been argued that adsorption thermodynamics should not be distinct from solution thermodynamics, and that adsorbents are effectively solid solvents, because the difference between adsorption and dissolution is not always distinct $[58,78]$. To illustrate the difficulty in clearly distinguishing between adsorption and dissolution, consider the following systems: argon/graphite, hydrogen/tungsten, hydrogen/carbon, hydrogen/palladium, benzene/rubber, water/sodium chloride, and water/sulfuric acid [58]. Solution thermodynamics defines the reference state as the pressure, $p^{0}(\mathrm{~Pa})$, and loading, $q^{0}(\mathrm{~mol} / \mathrm{kg})$, at which the number of gas molecules per unit of volume, $p^{0} / R T\left(\mathrm{~mol} / \mathrm{m}_{\mathrm{gas}}^{3}\right)$, equals the number of adsorbate molecules per unit of volume, $\rho q^{0}\left(\mathrm{~mol} / \mathrm{m}_{\text {ads }}^{3}\right)$, with $\rho\left(\mathrm{kg} / \mathrm{m}^{3}\right)$ the density of the solvent or adsorbent based on the total (specific) volume [48]. The total (specific) volume is the volume that the adsorbate cannot intrude as a bulk liquid, typically determined pycnometrically by imbibition of a porous material in mercury at high pressure [79]. For zeolites, this total volume coincides with the unit cell volume (and $\rho$ coincides with the framework density). This choice of reference state yields a dimensionless Ostwald (i.e., solubility) coefficient, $L_{\mathrm{c}}=K_{\mathrm{H}} p^{0} / q^{0}=\rho K_{\mathrm{H}} R T$, as the ratio between the number of adsorbate molecules per unit of volume, $\rho K_{\mathrm{H}} p\left(\mathrm{~mol} / \mathrm{m}_{\text {ads }}^{3}\right)$, and the number of gas molecules per unit of volume, $p / R T$ $\left(\mathrm{mol} / \mathrm{m}_{\text {gas }}^{3}\right)$ [48]. Use of the Ostwald coefficient, $L_{\mathrm{c}}(\mathrm{l})$, is by no means limited to solution thermodynamics [46-49]; it also is frequently used in catalysis [23,50-52], gas chromatography [8-10,55], and molecular simulations [56,57]. It has been successfully used to compare the thermodynamics of a wide variety of systems, including the adsorption of various adsorbates on porous glass, activated carbon, alumina-silica cracking catalysts [46], and zeolites [80] and the dissolution of selected adsorbates in non-polar liquids [46,49].

The solution thermodynamics approach results in the following definition for the adsorption entropy (see Supplementary material, B):

$\Delta S_{\text {ads }}=R\left[1+\ln \left(R T \rho K_{\mathrm{H}_{0}}\right)\right]$.

A third approach, based on pore filling [47,64-66,81], defines the standard state as the pressure at which there are an equal number of molecules per unit of gas volume and per unit of accessible adsorbate volume. In marked contrast to the solution thermodynamics approach, it considers only the accessible pore volume, $V_{\mathrm{p}}\left(\mathrm{m}^{3} / \mathrm{kg}\right)$, instead of the total adsorbate volume, $1 / \rho$ $\left(\mathrm{m}^{3} / \mathrm{kg}\right)$, per unit of adsorbate mass. This accessible pore volume, $V_{\mathrm{p}}\left(\mathrm{m}^{3} / \mathrm{kg}\right)$, is inferred from helium, nitrogen, or argon adsorption through such methods as the $t$-plot method $[66,81]$ or DFT theory [67], or from crystallographic data [81]. It yields the following definition for adsorption entropy (see Supplementary material, B):

$\Delta S_{\text {ads }}=R\left\{1+\ln \left(\frac{R T K_{\mathrm{H}_{0}}}{V_{\mathrm{p}}}\right)\right\}$.

Even though it formally introduces an inconsistency between basic assumptions and the Van't Hoff equation (formula (1)) (see Supplementary material, B), the first $R$ term is frequently omitted from the definition of the adsorption entropy in the pore filling and solution thermodynamics approaches (formulas (4) and (5)).

A fourth approach is based on extrapolating a specific isotherm to the Henry regime [47,68-77], as exemplified by the popular Langmuir isotherm. It equates the reference loading, $q^{0}(\mathrm{~mol} / \mathrm{kg})$, with the saturation capacity, $q_{\mathrm{sat}}(\mathrm{mol} / \mathrm{kg})$, and uses a fixed reference pressure (typically $p^{0}=101325 \mathrm{~Pa}$ ) as standard state. This approach defines the adsorption entropy as (see Supplementary material, C):

$\Delta S_{\text {ads }}=R \ln \left(\frac{101325 K_{\mathrm{H}_{0}}}{q_{\mathrm{sat}}}\right)$.

In what follows we compare the values for the adsorption entropy as derived from solution thermodynamics (Eq. (4)), porefilling (Eq. (5)), and Langmuir isotherm (Eq. (6)) approaches.

For highly porous adsorbents like zeolites, the solution thermodynamics and pore-filling approach typically yield similar values for the adsorption entropy, also when expanding the comparison beyond Table $3 \mathrm{~A}$, so as to include experimental data from other studies (we compared data from several references $[64,81])$. Typically the Langmuir isotherm approach yields significantly lower adsorption entropies, even when the data set under consideration is expanded beyond Table 3A. More salient differences become evident when comparing the three approaches for assessing the adsorption at exterior surfaces.

\subsection{Interior and exterior surface thermodynamics on TON-type zeolites}

When the TON-type pores contain some $8 \mathrm{wt} \%$ of organic void filler [44], the accessible micropore volume $V_{\mathrm{p}}$ collapses from 95.7 to $0.16 \mathrm{~cm}^{3} / \mathrm{kg}$ [10]; that is, a mere 1.08 -fold increase in density $\rho$ results in a 600 -fold decrease in accessible micropore volume $V_{\mathrm{p}}$. As a result of this dramatic decrease 
Table 3

A comparison of definitions for adsorption entropy (Eqs. (4), (5) and (6)) for the associated Gibbs free energies of adsorption for (A) combined exterior and interior surface adsorption and for (B) exterior surface adsorption only of $n$-alkanes and methylalkanes at $473 \mathrm{~K}$. The pre-exponential Henry coefficient for alkanes exposed to both interior and exterior surface is $K_{\mathrm{H}_{0}}\left(\mathrm{~mol} / \mathrm{kg} \mathrm{Pa}\right.$ ), the Henry coefficient for alkanes only exposed to the exterior surface is $K_{\mathrm{H}_{0}}$ exterior $(\mathrm{mol} / \mathrm{kg}$ Pa) were reported by Ocakoglu et al. [10]; the pore volume and the framework density were $9.57 \times 10^{-5} \mathrm{~m}^{3} / \mathrm{kg}$ and $1968.7 \mathrm{~kg} / \mathrm{m}^{3}$, respectively for the fully accessible TON-type zeolite [10,95], and $1.60 \times 10^{-7} \mathrm{~m}^{3} / \mathrm{kg}$ and $2126.2 \mathrm{~kg} / \mathrm{m}^{3}$, respectively for the TON-type zeolite with only accessible exterior surface [10,95]. Only the solution thermodynamics approach (Eq. (4)) yields a higher Gibbs free energy (a less negative value) for the exterior as compared to the interior surface, consistent with the lower Henry coefficient of the exterior as compared to the interior surface. The pore filling and Langmuir approaches (Eqs. (5) and (6)) yield a lower (more negative) Gibbs free energy for the exterior as compared to the interior surface, which is inconsistent with the dramatically lower Henry coefficient of the exterior surface

\begin{tabular}{|c|c|c|c|c|c|c|c|c|}
\hline Table 3A & & Eq. (4) & Eq. (5) & Eq. (6) & & Eq. (4) & Eq. (5) & Eq. (6) \\
\hline & $\begin{array}{l}K_{\mathrm{H}_{0}} \\
(\mathrm{~mol} / \mathrm{kg} \mathrm{Pa})\end{array}$ & $\begin{array}{l}\Delta S \\
(\mathrm{~J} / \mathrm{mol} \mathrm{K})\end{array}$ & $\begin{array}{l}\Delta S \\
(\mathrm{~J} / \mathrm{mol} \mathrm{K})\end{array}$ & $\begin{array}{l}\Delta S \\
(\mathrm{~J} / \mathrm{mol} \mathrm{K})\end{array}$ & $\begin{array}{l}\Delta H \\
(\mathrm{~kJ} / \mathrm{mol})\end{array}$ & $\begin{array}{l}\Delta G \\
(\mathrm{~kJ} / \mathrm{mol})\end{array}$ & $\begin{array}{l}\Delta G \\
(\mathrm{~kJ} / \mathrm{mol})\end{array}$ & $\begin{array}{l}\Delta G \\
(\mathrm{~kJ} / \mathrm{mol})\end{array}$ \\
\hline$n-\mathrm{C}_{5}$ & $2.7 \times 10^{-12}$ & -81.3 & -67.4 & -124.1 & -63.3 & -24.9 & -31.4 & -4.6 \\
\hline$n-\mathrm{C}_{6}$ & $2.7 \times 10^{-13}$ & -100.4 & -86.5 & -142.2 & -77.1 & -29.6 & -36.2 & -9.8 \\
\hline$n-\mathrm{C}_{7}$ & $3.7 \times 10^{-14}$ & -116.9 & -103.1 & -157.8 & -89.4 & -34.1 & -40.6 & -14.8 \\
\hline$n-\mathrm{C}_{8}$ & $7.5 \times 10^{-15}$ & -130.2 & -116.3 & -170.2 & -100.6 & -39.0 & -45.6 & -20.1 \\
\hline$n-\mathrm{C}_{9}$ & $1.3 \times 10^{-15}$ & -144.8 & -130.9 & -184.0 & -112.5 & -44.0 & -50.6 & -25.5 \\
\hline $2-\mathrm{Me}-\mathrm{C}_{4}$ & $1.5 \times 10^{-11}$ & -67.0 & -53.1 & -109.8 & -49.3 & -17.6 & -24.2 & 2.6 \\
\hline $2-\mathrm{Me}-\mathrm{C}_{5}$ & $2.6 \times 10^{-12}$ & -81.6 & -67.7 & -123.3 & -60.0 & -21.4 & -28.0 & -1.7 \\
\hline $2-\mathrm{Me}-\mathrm{C}_{6}$ & $1.5 \times 10^{-13}$ & -105.3 & -91.4 & -146.1 & -76.1 & -26.3 & -32.9 & -7.0 \\
\hline $2-\mathrm{Me}-\mathrm{C}_{7}$ & $2.4 \times 10^{-14}$ & -120.5 & -106.7 & -160.5 & -87.3 & -30.3 & -36.8 & -11.4 \\
\hline $2-\mathrm{Me}-\mathrm{C}_{8}$ & $4.5 \times 10^{-15}$ & -134.5 & -120.6 & -173.6 & -97.8 & -34.2 & -40.8 & -15.7 \\
\hline $3-\mathrm{Me}-\mathrm{C}_{5}$ & $2.4 \times 10^{-12}$ & -82.3 & -68.4 & -124.1 & -59.4 & -20.5 & -27.1 & -0.7 \\
\hline $3-\mathrm{Me}-\mathrm{C}_{6}$ & $3.0 \times 10^{-13}$ & -99.5 & -85.7 & -140.4 & -72.0 & -24.9 & -31.5 & -5.6 \\
\hline $3-\mathrm{Me}-\mathrm{C}_{7}$ & $3.6 \times 10^{-14}$ & -117.2 & -103.3 & -157.2 & -84.5 & -29.1 & -35.6 & -10.1 \\
\hline $3-\mathrm{Me}-\mathrm{C}_{8}$ & $4.0 \times 10^{-15}$ & -135.4 & -121.6 & -174.6 & -97.8 & -33.7 & -40.3 & -15.2 \\
\hline \multirow[t]{2}{*}{ Table 3B } & & Eq. (4) & Eq. (5) & Eq. (6) & & Eq. (4) & Eq. (5) & Eq. (6) \\
\hline & $\begin{array}{l}K_{\mathrm{H}_{0}} \text { exterior } \\
(\mathrm{mol} / \mathrm{kg} \mathrm{Pa})\end{array}$ & $\begin{array}{l}\Delta S_{\text {ext }} \\
(\mathrm{J} / \mathrm{mol} \mathrm{K})\end{array}$ & $\begin{array}{l}\Delta S_{\text {ext }} \\
(\mathrm{J} / \mathrm{mol} \mathrm{K})\end{array}$ & $\begin{array}{l}\Delta S_{\text {ext }} \\
(\mathrm{J} / \mathrm{mol} \mathrm{K})\end{array}$ & $\begin{array}{l}\Delta H_{\text {ext }} \\
(\mathrm{kJ} / \mathrm{mol})\end{array}$ & $\begin{array}{l}\Delta G_{\text {ext }} \\
(\mathrm{kJ} / \mathrm{mol})\end{array}$ & $\begin{array}{l}\Delta G_{\text {ext }} \\
(\mathrm{kJ} / \mathrm{mol})\end{array}$ & $\begin{array}{l}\Delta G_{\text {ext }} \\
(\mathrm{kJ} / \mathrm{mol})\end{array}$ \\
\hline$n-\mathrm{C}_{5}$ & $2.7 \times 10^{-12}$ & -80.6 & -14.2 & -70.9 & -47.7 & -9.6 & -41.0 & -14.1 \\
\hline$n-\mathrm{C}_{6}$ & $4.0 \times 10^{-13}$ & -96.5 & -30.1 & -85.8 & -58.5 & -12.8 & -44.3 & -17.9 \\
\hline$n-\mathrm{C}_{7}$ & $4.1 \times 10^{-14}$ & -115.5 & -49.1 & -103.8 & -70.9 & -16.3 & -47.7 & -21.8 \\
\hline$n-\mathrm{C}_{8}$ & $7.3 \times 10^{-15}$ & -129.8 & -63.4 & -117.2 & -81.7 & -20.3 & -51.7 & -26.2 \\
\hline$n-\mathrm{C}_{9}$ & $1.2 \times 10^{-15}$ & -144.8 & -78.4 & -131.5 & -92.7 & -24.2 & -55.6 & -30.5 \\
\hline $2-\mathrm{Me}-\mathrm{C}_{4}$ & $1.3 \times 10^{-12}$ & -86.7 & -20.3 & -76.9 & -47.7 & -6.7 & -38.1 & -11.3 \\
\hline $2-\mathrm{Me}-\mathrm{C}_{5}$ & $1.7 \times 10^{-13}$ & -103.6 & -37.2 & -92.8 & -59.1 & -10.1 & -41.5 & -15.2 \\
\hline $2-\mathrm{Me}-\mathrm{C}_{6}$ & $2.0 \times 10^{-14}$ & -121.4 & -55.0 & -109.7 & -71.1 & -13.7 & -45.1 & -19.2 \\
\hline $2-\mathrm{Me}-\mathrm{C}_{7}$ & $3.7 \times 10^{-15}$ & -135.5 & -69.1 & -122.8 & -81.0 & -16.9 & -48.3 & -22.9 \\
\hline $2-\mathrm{Me}-\mathrm{C}_{8}$ & $3.6 \times 10^{-16}$ & -154.8 & -88.4 & -141.4 & -93.7 & -20.5 & -51.9 & -26.8 \\
\hline $3-\mathrm{Me}-\mathrm{C}_{5}$ & $2.3 \times 10^{-13}$ & -101.1 & -34.7 & -90.4 & -57.2 & -9.4 & -40.8 & -14.4 \\
\hline $3-\mathrm{Me}-\mathrm{C}_{6}$ & $1.0 \times 10^{-14}$ & -127.2 & -60.8 & -115.5 & -69.9 & -9.7 & -41.1 & -15.3 \\
\hline $3-\mathrm{Me}-\mathrm{C}_{7}$ & $2.2 \times 10^{-15}$ & -139.8 & -73.4 & -127.3 & -83.2 & -17.1 & -48.5 & -23.0 \\
\hline $3-\mathrm{Me}-\mathrm{C}_{8}$ & $4.9 \times 10^{-16}$ & -152.3 & -85.9 & -138.9 & -93.6 & -21.6 & -53.0 & -27.9 \\
\hline
\end{tabular}

in micropore volume, $K_{\mathrm{H}_{0}} / V_{\mathrm{p}}$ and $K_{\mathrm{H}_{0}} / q_{\text {sat }}$ increase, the adsorption entropies based on both the pore filling and the Langmuir isotherm approaches increase (i.e., become less negative, Eqs. (5) and (6)), and the Gibbs free energies based on the pore-filling and Langmuir isotherm approaches decrease (i.e., become more negative; Table 3) when adsorption is restricted to the exterior surface. This more negative Gibbs free energy indicates that exterior surface adsorption is thermodynamically preferred over interior surface adsorption (Table 3), which is inconsistent with the dramatically lower Henry coefficients for exterior surface adsorption compared with interior surface adsorption (Table 1). In contrast, the total adsorbent volume per unit of mass (and the total density) hardly change when adsorption is restricted to the exterior surface, so that the change in Henry coefficient dominates the changes in the Ostwald co- efficient and thermodynamic parameters derived through the solution thermodynamics approach: The adsorption entropy based on total adsorbent volume (Eq. (4)) decreases, and the Gibbs free energy of adsorption based on total adsorbent volume increases (i.e., becomes less negative) when adsorption is restricted to the exterior surface (Table 3). This less-negative Gibbs free energy indicates that the exterior surface is thermodynamically less preferred than the interior surface, which is consistent with the dramatically lower Henry coefficients for exterior surface adsorption (Table 1). Accordingly, the Gibbs free energy of adsorption and the adsorption entropy based on the total adsorbent volume as derived from solution thermodynamics are most consistent with the reported Henry coefficients (Table 1) and are most suitable for use in further analyses. 


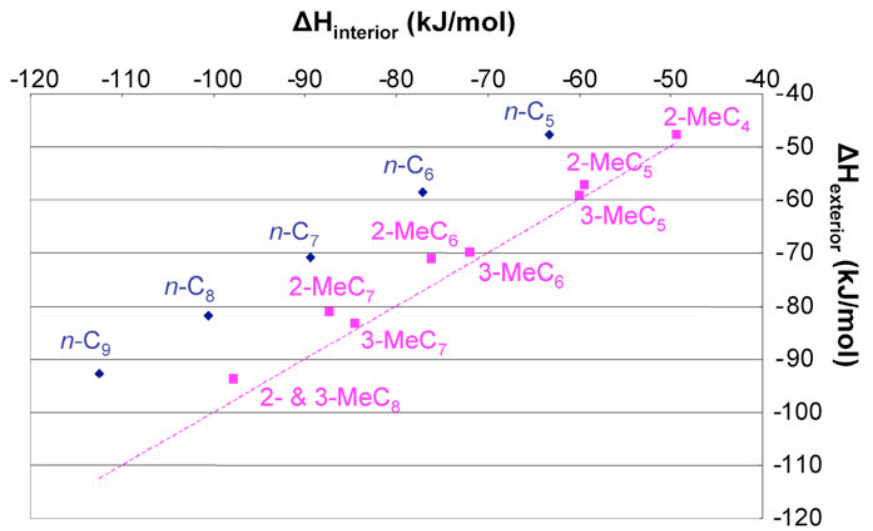

(A)

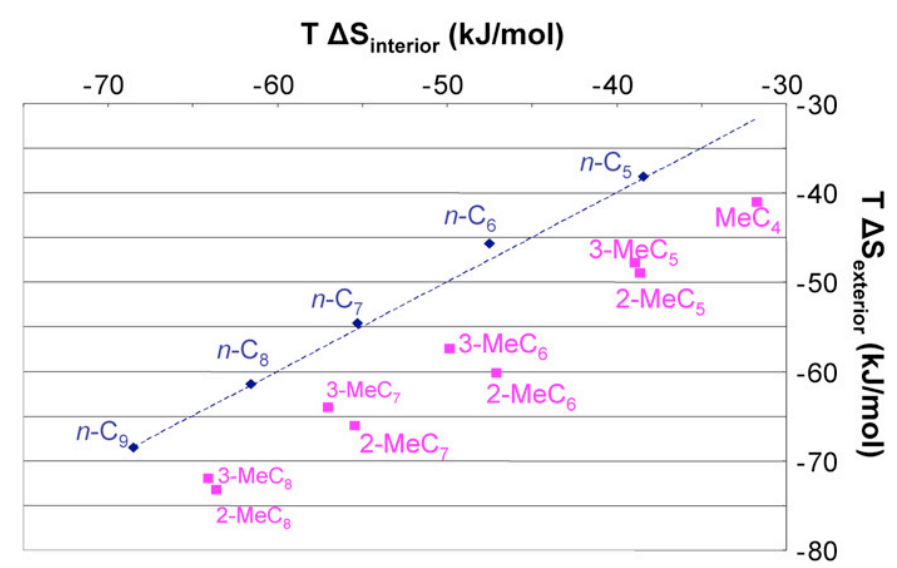

(B)

Fig. 3. (A) A comparison of the adsorption enthalpies at the interior, $\Delta H_{\text {interior }}$ $(\mathrm{kJ} / \mathrm{mol})$, and at the exterior surface, $\Delta H_{\text {exterior }}(\mathrm{kJ} / \mathrm{mol})$, of TON-type zeolites at $473 \mathrm{~K}$ as reported by Ocakoglu et al. $[9,10]$ illustrates that $n$-alkanes favor adsorption at the interior surface because of its lower adsorption enthalpy, whereas the adsorption enthalpy of methylalkanes is close to the $\Delta H_{\text {exterior }}=\Delta H_{\text {interior }}$ line. (B) A comparison of the product of the temperature $(T=473 \mathrm{~K})$ and the adsorption entropies at the interior, $T \Delta S_{\text {interior }}$ $(\mathrm{kJ} / \mathrm{mol})$, and at the exterior surface, $T \Delta S_{\text {exterior }}(\mathrm{kJ} / \mathrm{mol})$, of TON-type zeolites illustrates that methylalkanes favor adsorption at the interior surface because of its higher (less negative) adsorption entropy, whereas the adsorption entropy of $n$-alkanes is close to the $T \Delta S_{\text {exterior }}=T \Delta S_{\text {interior line. }}$

Having established the most appropriate definition for the adsorption entropy, we can evaluate the individual contributions of the interior and exterior TON-type zeolite surfaces to the adsorption enthalpy and entropy. For linear alkanes, the adsorption enthalpy is some $11.8 \mathrm{~kJ} / \mathrm{mol}$ lower at the interior surface compared with the exterior surface, but the adsorption entropy is virtually identical on the two surfaces (Fig. 3; Table 3). Apparently, the driving force causing linear alkanes to leave the exterior for the interior surface is nearly exclusively the lower adsorption enthalpy due to the stabilizing Van der Waals forces inside the TON-type pores. In contrast, mono-methylalkanes exhibit a similar adsorption enthalpy at the interior and exterior surfaces, but an $11-\mathrm{kJ} / \mathrm{mol}$ higher $T \Delta S$ at the exterior surface (Fig. 3B). Apparently, the driving force behind the migration of mono-methylalkanes from the exterior surface to the interior surface is almost exclusively a gain in mobility. The fact that they apparently adsorb in a more rigid fashion at the exterior surface than at the interior surface suggests that they form some
Table 4

Henry coefficients for TON-, $K_{\mathrm{H}}$ TON $(\mathrm{mol} / \mathrm{kg}$ Pa) and for MTT-type zeolites, $K_{\text {H MTT }}(\mathrm{mol} / \mathrm{kg} \mathrm{Pa})$ at $523 \mathrm{~K}$ as reported by Ocakoglu et al. [9,10]

\begin{tabular}{lll}
\hline & $K_{\mathrm{H} \mathrm{TON}}(\mathrm{mol} / \mathrm{kg} \mathrm{Pa})$ & $K_{\mathrm{H} \text { MTT }}(\mathrm{mol} / \mathrm{kg} \mathrm{Pa})$ \\
\hline$n-\mathrm{C}_{5}$ & $5.40 \times 10^{-6}$ & $5.20 \times 10^{-6}$ \\
$n-\mathrm{C}_{6}$ & $1.30 \times 10^{-5}$ & $1.50 \times 10^{-5}$ \\
$n-\mathrm{C}_{7}$ & $3.20 \times 10^{-5}$ & $3.80 \times 10^{-5}$ \\
$n-\mathrm{C}_{8}$ & $8.70 \times 10^{-5}$ & $8.40 \times 10^{-5}$ \\
$2-\mathrm{Me}-\mathrm{C}_{4}$ & $1.20 \times 10^{-6}$ & $1.70 \times 10^{-6}$ \\
$2-\mathrm{Me}-\mathrm{C}_{5}$ & $2.40 \times 10^{-6}$ & $4.10 \times 10^{-6}$ \\
$2-\mathrm{Me}-\mathrm{C}_{6}$ & $5.90 \times 10^{-6}$ & $1.00 \times 10^{-5}$ \\
$2-\mathrm{Me}-\mathrm{C}_{7}$ & $1.20 \times 10^{-5}$ & $2.50 \times 10^{-5}$ \\
$3-\mathrm{Me}-\mathrm{C}_{5}$ & $2.10 \times 10^{-6}$ & $3.60 \times 10^{-6}$ \\
$3-\mathrm{Me}-\mathrm{C}_{6}$ & $4.30 \times 10^{-6}$ & $8.90 \times 10^{-6}$ \\
$3-\mathrm{Me}-\mathrm{C}_{7}$ & $9.50 \times 10^{-6}$ & $2.00 \times 10^{-5}$ \\
\hline
\end{tabular}

epitaxial layer at the outside zeolite surface, perhaps through adsorption with a methyl group sticking into a pore mouth. So far, the existence of such an epitaxial layer of methyl alkanes at the exterior surface of TON-type zeolites has been corroborated only for alkanes with geminal methyl groups that are too large to access the TON-type interior surface [45]. The existence of an epitaxial exterior surface layer of methylalkanes has long been advocated by the proponents of pore mouth and key-lock catalysis. The adsorption data appear to corroborate the existence of such an epitaxial layer, but they also indicate that the layer constitutes too small a fraction of the adsorbed alkanes to be catalytically relevant.

\subsection{Adsorption at MTT-type and TON-type zeolites}

Having quantified the extent of exterior and interior surface alkane adsorption on TON-type zeolites, we now reanalyze the adsorption data on MTT-type zeolites. It has been argued that MTT-type zeolites cannot adsorb methylalkanes, because these compounds exhibit similar enthalpy in MTT-type zeolites as at the exterior surface of TON-type zeolites $[9,11]$. Although the branched alkanes indeed exhibit similar adsorption enthalpy in MTT-type zeolites and at the exterior surface of TON-type zeolites, adsorption entropy must be considered before any conclusion can be reached. A more straightforward approach is to compare the primary Henry coefficients directly (Table 4; Fig. 4). The Henry coefficients of the linear alkanes are identical for TON- and MTT-type zeolites. The Henry coefficients of the mono-methylalkanes are somewhat higher for the MTT-type zeolites compared with the TON-type zeolites, corresponding to a somewhat lower Gibbs free energy of adsorption (Tables 4 and 5). Given the identical adsorption enthalpy of mono-methylalkanes for TON- and MTT-type zeolites, this suggests that mono-methylalkanes lose a little less entropy on absorption into MTT-type zeolites compared with adsorption into TON-type zeolites. Moreover, the linear alkanes lose somewhat less entropy on adsorption into MTT-type zeolites, but this entropy loss is fully offset by a somewhat lower enthalpy gain (Table 5). In general, differences in adsorption properties between the two structures are subtle (as are the differences between the structures, and their catalysis [4]), and they are inconsistent with the notion that methylalkanes 


\section{$\mathrm{K}_{\mathrm{H}}(\mathrm{mol} / \mathrm{kg} \mathrm{Pa})$ TON at $523 \mathrm{~K}$}

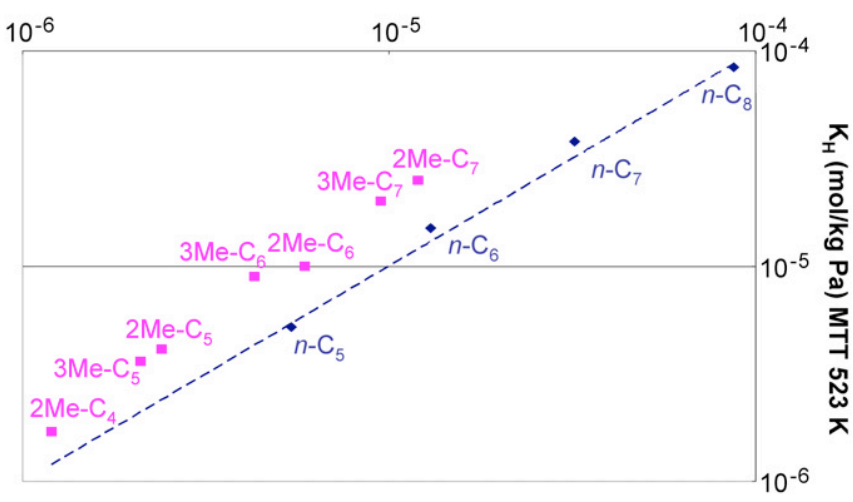

Fig. 4. The Henry coefficients of $n$ - and methylalkanes on TON- and MTT-type zeolites at $523 \mathrm{~K}$ as reported by Ocakoglu et al. [9,10] are quite similar. If anything, methylalkanes prefer MTT- to TON-type zeolites.

enter TON- but not MTT-type zeolites (as suggested in [11]). It suggests that the remarkably low $n$-alkane and the absent methylalkane adsorption reported for MTT-type zeolites at saturation pressure at $298 \mathrm{~K}$ [11] reflect adsorption kinetics more than thermodynamics (Table 2). The intrusion of kinetic effects likely is compounded by the remarkably low MTT-type zeolite micropore volume $(0.034 \mathrm{cc} / \mathrm{g}$ [11] as opposed to a more usual $0.06 \mathrm{cc} / \mathrm{g}$ [24]), suggesting that not all of the pore volume of the particular MTT-type zeolite sample used in the high-pressure study was accessible.

\subsection{Catalysis on TON-and MTT-type zeolites with inactivated exterior surface}

So far, we have evaluated the contributions of the exterior and interior surfaces to adsorption thermodynamics as a way of evaluating their effect on the dramatically more dynamic system during catalysis. This approach ignores complications due to, for example, kinetic limitations, coking, and skewed catalytically active site distributions. Naturally, the most immediate way to evaluate the relative contributions of exterior and interior surfaces to catalysis is to selectively remove catalytically active sites from the exterior surface [19-21]. This has been accomplished through the selective extraction of aluminum from the exterior surface of a TON-type zeolite [25]
Table 6

$n$-Hexadecane conversion on TON-type zeolites with an exterior surface from which aluminum (catalytically active sites) has been selectively acid-extracted to various degrees as reported by Sastre et al. [25]. Exterior surface aluminum densities were calculated assuming that the bulk, $\mathrm{Al} /(\mathrm{Si}+\mathrm{Al})(\mathrm{mol} / \mathrm{mol})$, and surface aluminum concentration, $\mathrm{Al} /(\mathrm{Si}+\mathrm{Al})$ exterior $(\mathrm{mol} / \mathrm{mol})$, were identical for the non-extracted sample, T1. The extent of exterior surface dealumination does not affect the temperature required to achieve 30 or $50 \%$ $n$-hexadecane conversion or the isomerization selectivity, $\%$ isom at $50 \% n$ - $\mathrm{C}_{16}$ conv, which indicate that the exterior surface contribution to $n$-hexadecane hydroconversion is negligible

\begin{tabular}{llll}
\hline Sample ID & T1 & T1A & T5A \\
\hline $100 \times \mathrm{Al} /(\mathrm{Si}+\mathrm{Al})(\mathrm{mol} / \mathrm{mol})$ & 2.6 & 2.0 & 1.8 \\
$100 \times \mathrm{Al} /(\mathrm{Si}+\mathrm{Al})$ exterior $(\mathrm{mol} / \mathrm{mol})$ & 2.6 & 1.3 & 0.9 \\
$T_{\text {req } 30 \% \text { conv }}(\mathrm{K})$ & 540 & 541 & 543 \\
$T_{\text {req } 50 \% \text { conv }}(\mathrm{K})$ & 548 & 549 & 549 \\
$\%$ isom at $50 \%$ - $\mathrm{C}_{16}$ conv & 43 & 42 & 43 \\
\hline
\end{tabular}

and through the epitaxial growth of MTT-type silica on top of MTT-type zeolite [4]. The $n$-alkane hydroconversion on both of these catalysts is worth revisiting because it either has not received due recognition [25] or because it needs to be reinterpreted in the light of our current understanding of the extent of $n$-alkane adsorption at the exterior and interior surfaces of TON- and MTT-type zeolites.

The extent of extraction with a mineral acid of aluminum from the exterior and interior surfaces of a TON-type zeolite has been evaluated with di-tert-butyl-pyridine adsorption and with bulk chemical analysis [25]. Di-tert-butyl-pyridine is a bulky, strongly basic probe molecule that has access only to the exterior TON-type zeolite surface and thus affords quantification of the acid site density at the exterior surface. Assuming that each aluminum atom is associated with a catalytically active acid site, bulk chemical analysis probes the reduction in overall acid site density [25]. Interestingly, quantification of the acid site densities at the exterior surface and in the bulk of TON-type zeolites indicates that a dramatic reduction in the acid site density at the exterior surface does not significantly affect the activity, selectivity, or activation energy of $n$-hexadecane hydroconversion (Table 6). Clearly, the minimal changes in $n$-hexadecane conversion more closely reflect the minimal changes in the bulk acid site density than the dramatic changes in the exterior surface acid site density (Table 6). This strongly suggests that

Table 5

Gibbs free energy of adsorption, $\Delta G(\mathrm{~kJ} / \mathrm{mol})$, adsorption enthalpy, $\Delta H(\mathrm{~kJ} / \mathrm{mol})$, and adsorption entropy, $\Delta S(\mathrm{~J} / \mathrm{mol} \mathrm{K})$, for TON- and MTT-type zeolites at $523 \mathrm{~K}$ calculated using Eq. (4) from data reported by Ocakoglu et al. [9-11]. The framework densities for TON- and MTT-type zeolites are $1968.7 \mathrm{~kg} / \mathrm{m}^{3}$ and $1995.5 \mathrm{~kg} / \mathrm{m}^{3}$, respectively [95]

\begin{tabular}{|c|c|c|c|c|c|c|}
\hline & $\begin{array}{l}\Delta G \text { TON } \\
(\mathrm{kJ} / \mathrm{mol})\end{array}$ & $\begin{array}{l}\Delta G \mathrm{MTT} \\
(\mathrm{kJ} / \mathrm{mol})\end{array}$ & $\begin{array}{l}\Delta H \text { TON } \\
(\mathrm{kJ} / \mathrm{mol})\end{array}$ & $\begin{array}{l}\Delta H \mathrm{MTT} \\
(\mathrm{kJ} / \mathrm{mol})\end{array}$ & $\begin{array}{l}\Delta S \text { TON } \\
(\mathrm{kJ} / \mathrm{mol} \mathrm{K})\end{array}$ & $\begin{array}{l}\Delta S \text { MTT } \\
(\mathrm{kJ} / \mathrm{mol} \mathrm{K})\end{array}$ \\
\hline$n-\mathrm{C}_{5}$ & -21.0 & -20.9 & -63.3 & -58.5 & -81 & -72 \\
\hline$n-\mathrm{C}_{6}$ & -24.8 & -25.5 & -77.1 & -72.7 & -100 & -90.1 \\
\hline$n-\mathrm{C}_{7}$ & -28.8 & -29.6 & -89.4 & -84.0 & -117 & -104 \\
\hline$n-\mathrm{C}_{8}$ & -33.1 & -33.0 & -100.6 & -94.3 & -130 & -117 \\
\hline $2-\mathrm{Me}-\mathrm{C}_{4}$ & -14.5 & -16.1 & -49.3 & -49.4 & -67 & -64 \\
\hline $2-\mathrm{Me}-\mathrm{C}_{5}$ & -17.5 & -19.9 & -60.0 & -61.3 & -81 & -79 \\
\hline $2-\mathrm{Me}-\mathrm{C}_{6}$ & -21.4 & -23.8 & -76.1 & -76.2 & -105 & -100 \\
\hline $2-\mathrm{Me}-\mathrm{C}_{7}$ & -24.5 & -27.7 & -87.3 & -87.9 & -121 & -115 \\
\hline $3-\mathrm{Me}-\mathrm{C}_{7}$ & -23.5 & -26.8 & -84.5 & -86.8 & -117 & -115 \\
\hline
\end{tabular}


Table 7

n-Decane conversion on two MTT-type zeolites, "HZSM-23" and "ZSM-23" and on sample "ZSM-23" coated with MTT-type silica as reported Ernst et al. [43] and by Huybrechts et al. [4]. The silica coating decreases the aluminum density at the exterior surface, the $n$-decane hydroconversion activity (increases the temperature required to reach either 30 or $50 \% n$-decane conversion), the hydroisomerization selectivity (at $50 \% n$-decane conversion), and the activation energy, $E_{\text {act }}(\mathrm{kJ} / \mathrm{mol})$. Contrary to the stipulations of pore mouth and key-lock catalysis, there is no straightforward relationship between the methylnonane yield structure (under the heading $\mathrm{Me}-\mathrm{C}_{9}$ yield at $30 \%$ conversion) and the activation energy

\begin{tabular}{|c|c|c|c|}
\hline MTT-type zeolite sample ID & HZSM-23 & ZSM-23 & MTT Si \\
\hline Reference, source of data & [43] & [4] & [4] \\
\hline$n-\mathrm{C}_{10}$ feed rate $(\mathrm{mol} / \mathrm{kg} \mathrm{s})$ & $6.94 \times 10^{-4}$ & $3.85 \times 10^{-4}$ & $3.85 \times 10^{-4}$ \\
\hline $\mathrm{p} \mathrm{H}_{2}(\mathrm{kPa})$ & 100 & 449 & 449 \\
\hline $\mathrm{p} n-\mathrm{C}_{10}(\mathrm{kPa})$ & 1.3 & 1.2 & 1.2 \\
\hline $100 \times \mathrm{Al} /(\mathrm{Si}+\mathrm{Al})(\mathrm{mol} / \mathrm{mol})$ & 0.45 & 1.69 & 1.49 \\
\hline $\begin{array}{l}100 \times \mathrm{Al} /(\mathrm{Si}+\mathrm{Al}) \\
\text { exterior }(\mathrm{mol} / \mathrm{mol})\end{array}$ & n.d. & 2.6 & 0.46 \\
\hline$T_{\text {req } 30 \% n-\mathrm{C} 10 \mathrm{conv}}(\mathrm{K})$ & 481 & 465 & 492 \\
\hline$T_{\text {req } 50 \% n-\mathrm{C} 10 \mathrm{conv}}(\mathrm{K})$ & 489 & 472 & 500 \\
\hline$\%$ isom at $50 \% n-\mathrm{C}_{10}$ conv & 50 & 41 & 37 \\
\hline$E_{\text {act }}(\mathrm{kJ} / \mathrm{mol})$ & 158 & 180 & 155 \\
\hline \multicolumn{4}{|l|}{ Me- $\mathrm{C}_{9}$ yield at $30 \%$ conv } \\
\hline $2-\mathrm{Me}-\mathrm{C}_{9}$ & 41.3 & 53.3 & 49.9 \\
\hline $3-\mathrm{Me}-\mathrm{C}_{9}$ & 30.4 & 28.0 & 28.1 \\
\hline $4-\mathrm{Me}-\mathrm{C}_{9}$ & 17.2 & 10.8 & 13.1 \\
\hline $5-\mathrm{Me}-\mathrm{C}_{9}$ & 11.1 & 7.9 & 8.9 \\
\hline
\end{tabular}

the exterior TON-type zeolite surface contributes little to the overall $n$-hexadecane hydroconversion, and that all hydroconversion occurs at the interior TON-type zeolite surface.

At first glance, the MTT-type zeolites differ markedly from the TON-type zeolites (cf. Tables 6 and 7); when the exterior surface of MTT-type zeolites is covered with MTT-type silica, the $n$-decane hydroconversion activity, hydroisomerization selectivity, and activation energy all decrease significantly (Table 7; cf. ZSM-23 and MTT Si). These difference are all the more remarkable considering that $n$-alkane hydroconversion usually exhibits similar activity and selectivity on MTT-type zeolites as on TON-type zeolites [14]. In principle, the combination of lower activity, isomerization selectivity, and activation energy epitomizes the onset of diffusion limitations [82-84]. But the pore mouth and key-lock catalysis model precludes diffusion limitations and stipulates that all alkane hydroconversion reactions occur through transition states located in an alkane layer adsorbed at the exterior surface [4,7]. Assuming that the pore mouth and key-lock catalysis model applies, the decreased activity can be attributed only to the lower acid site density at the exterior surface, and the decreased in hydroisomerization selectivity and activation energy can be attributed to a change in reaction mechanism (and associated energy levels of the transition states) [4]. Indeed, the decreased activation energy due to silica-coating of the MTT-type zeolites can be attributed to a decrease in the true activation energy as a result of a temperature-induced shift in selectivity from 2- to 4- and 5-methylnonane [4]. But this explanation is inconsistent with a sample exhibiting similarly low activation energy and even lower 2- and even higher 4- and 5-methylnonane yields at lower temperatures (Table 7; cf. HZSM-23 and MTT Si) [43]. The apparent absence of a direct link between activation energy and methylnonane selectivity indicates that the activation energies are not true activation energies, but apparent activation energies. In contrast to true activation energies, apparent activation energies also can reflect differences in the reactant loading of the catalytically active sites [85], as well as the extent of diffusion limitations [82-84]. Thus, the higher apparent activation energy of ZSM-23 compared with HZSM-23 may be due to a higher order in $n$-decane as a result of the lower reactant coverage of its higher-density acid sites (Table 7). The higher apparent activation energy of ZSM-23 compared with MTT Si could be due to a less diffusion-limited reaction resulting from the absence of an MTT-type silica shell, which lengthens the diffusion pathway between the acid sites at the MTT-type zeolite core and the reactants coming from the relatively inert exterior surface of the MTT Si sample (Table 7). A more rigorous explanation would require a more extensive kinetic study; however, such a kinetic study could not restore the clear correlation between activation energy and selectivity (and operation temperature) that is required for the pore mouth and key-lock catalysis model to apply (Table 7).

Although the pore mouth and key-lock catalysis model does not apply to TON- and MTT-type zeolites, it could apply to zeolites with apertures so small that they do exclude methylalkanes. It is generally accepted that the $0.38 \mathrm{~nm}$ apertures of CHAtype molecular sieves are small enough to categorically exclude methylalkanes from the interior surface [86]. Recent experimental studies corroborate molecular simulations indicating that CHA-type molecular sieves also contain too many of these narrow apertures per $n$-alkane to afford the complete adsorption of $n$-octane or $n$-decane [ $16,17,53,87]$, so that the conversion of $n$-octane and $n$-decane is indeed likely to be limited to the exterior surface and should afford an example of pore mouth and key-lock catalysis. In agreement with catalysis occurring exclusively at the small exterior surface of CHA-type molecular sieves, CHA-type sieves exhibit a dramatically lower $n$-octane and $n$-decane conversion activity than sieves with apertures large enough to accommodate reactants and products fully at their large interior surface [88-90]. From what little data are available on pore mouth and key-lock catalysis with CHA-type silicoaluminophosphates, it appears that these sieves favor hydrocracking more than hydroisomerization $[89,90]$. Pore mouth and key-lock catalysis would predict that the selectivity should shift toward hydroisomerization when a sieve is used in which CHA-sized apertures are more widely dispersed across the exterior crystal surface.

Like CHA-type sieves, ERI-type zeolites have apertures small enough to categorically exclude methylalkanes [86] and have cages small enough to exclude $n$-alkanes the size of $n$-hexatriacontane [16,17]. Nevertheless, ERI-type cages reportedly leave their signature on the fragments cracked off from very long $n$-alkanes [91], suggesting some form of pore mouth and key-lock catalysis. It would be interesting to explore whether such selectivity could be extended to other zeolites, so as to identify more examples of pore mouth and key-lock catalysis and thereby gain insight into these interesting concepts. 


\section{Conclusion}

Our analysis of experimentally determined loadings at any pressure has demonstrated that $n$-alkanes, methylalkanes, and possibly vicinal dimethylalkanes have full access to the interior surfaces of TON- and MTT-type zeolites. Regardless of pressure, exterior surface adsorption of these alkane isomers is negligible compared with interior surface adsorption. This conclusion was never drawn before, in part because of disagreement on how best to define the adsorption entropy and, by extension, the Gibbs free energy of adsorption. We have established that the definition of adsorption entropy used in solution thermodynamics affords an equitable comparison of exterior surface and interior surface adsorption. According to this definition, $n$-alkanes exhibit similar adsorption entropy at the interior and exterior surfaces of TON-type zeolites, but they gain enthalpy by vacating the exterior surface for the interior surface. Methylalkanes exhibit similar adsorption enthalpy at the interior and exterior zeolite surfaces, but they gain entropy by leaving the exterior surface for the interior surface. Thus, $n$-alkanes prefer the interior surface for its stabilizing Van der Waals interactions, whereas methylalkanes prefer it for its higher mobility. The comparative lack of mobility of the methylalkanes adsorbed at the exterior surface strongly suggests that they are locked by, for example, having part of their anatomy stuck into the pore mouths. Such immobilization corroborates one of the key tenets of the pore mouth and key-lock catalysis model, while also indicating that the thermodynamic penalty for such low mobility is so great that it does not occur to an appreciable extent unless the interior surface is already loaded with competing adsorbents.

MTT-type zeolites exhibit Henry coefficients, adsorption enthalpies, and entropies of $n$-alkanes and of methylalkanes remarkably similar to those for TON-type zeolites. Because both $n$ - and methylalkanes have full access to the interior surface of TON-type zeolites, the similarity in adsorption properties strongly suggests that both alkane isomers also have full access to the interior surface of MTT-type zeolites.

It is important to note that the adsorption experiments and the simulations cannot address the full complexity of a zeolite at catalytic conversion conditions, which can involve intrusion of pore blocking through coke formation or of heterogeneous distributions of catalytically active sites, as well as other deviations from an ideal clean crystal. Therefore, a catalytic study needs to complement the adsorption study.

The negligible impact on $n$-decane hydroconversion of a dramatic reduction in the density of catalytically active sites on the exterior surface of a TON-type zeolites indicates that the exterior TON-type surface contributes little to $n$-alkane hydroconversion, and that the interior TON-type zeolite surface dominates both adsorption and $n$-alkane hydroconversion. The dramatic decrease in activation energy, activity, hydroisomerization selectivity, and activation energy due to an epitaxial MTT-type silica coating on top of MTT-type zeolite cannot be reconciled with pore mouth and key-lock catalysis and suggests the onset of diffusion limitations as a result of an increase in diffusion path length between exterior surface and catalytically ac- tive sites at the MTT-type zeolite core. Diffusion limitations are incompatible with pore mouth and key-lock catalysis, because pore mouth catalysis assumes that all catalysis occurs at transition states at specific positions at the exterior surface. Thus, catalysis with both TON- and MTT-type zeolites with a deactivated exterior surface corroborates the findings of adsorption experiments indicating a negligible contribution to adsorption and catalysis of the exterior surface.

Pore mouth and key-lock catalysis should apply to, for example, long alkane conversion on CHA-type molecular sieves, and exterior surface catalysis could explain the low activity and high hydrocracking selectivity of these sieves compared with sieves with apertures large enough to provide full access to their interior surface. It would be interesting to extend the experimental database and, say, evaluate to what extent CHAtype zeolites crack very long $n$-alkanes as shape-selectively as ERI-type zeolites (cf. Ref. [91]). CHA- and ERI-type zeolites contain cages accessible through $\sim 0$.4-nm-wide windows. If molecular sieves with $\sim 0.4$-nm-diameter tubular channels instead of cage-containing topologies are preferred, then ATNtype sieves should be of interest [92]. It may be too early to evaluate the potential for processing alkane shape selectively at the exterior surface of zeolites, but the external zeolite surface clearly has the potential to expand the utility of concepts associated with shape-selective external surface catalysis, including cage effects [16,53], nest effects [93], pore mouth and key-lock catalysis [4-11,13,14], length-selective cracking [54], and length exclusion [87].

\section{Acknowledgments}

This work was supported in part by the EC through a Marie Curie Excellence Grant (MEXT-CT-2005-023311). The authors thank the European Commission for an ERG (to S.C.), and also thank J.A.R. van Veen, C.H. Roemkens, C. Wilson, A.F. Kuperman, and S.I. Zones for their valuable comments on the manuscript.

\section{Supplementary material}

The online version of this article contains additional supplementary material.

Please visit DOI: 10.1016/j.jcat.2008.03.004.

\section{References}

[1] B. Smit, T.L.M. Maesen, Nature 451 (2008) 671-678.

[2] P.B. Weisz, V.J. Frilette, J. Phys. Chem. 64 (1960) 382-383.

[3] D. Fraenkel, Ind. Eng. Chem. Res. 29 (1990) 1814-1821.

[4] W. Huybrechts, J.W. Thybaut, B.R. De Waele, G. Vanbutsele, K.J. Houthoofd, F. Bertinchamps, J.F.M. Denayer, E.M. Gaigneaux, G.B. Marin, G.V. Baron, P.A. Jacobs, J.A. Martens, J. Catal. 239 (2006) 451459.

[5] J.F. Denayer, W. Souverijns, P.A. Jacobs, J.A. Martens, G.V. Baron, J. Phys. Chem. B 102 (1998) 4588-4597.

[6] J.A. Martens, R. Parton, L. Uytterhoeven, P.A. Jacobs, G.F. Froment, Appl. Catal. 76 (1991) 95-116. 
[7] J.A. Martens, W. Souverijns, W. Verrelst, R. Parton, G.F. Groment, P.A. Jacobs, Angew. Chem. Int. Ed. Engl. 34 (1995) 2528-2530.

[8] J.F. Denayer, G.V. Baron, J.A. Martens, P.A. Jacobs, J. Phys. Chem. B 102 (1998) 3077-3081.

[9] R. Ocakoglu, J.F.M. Denayer, J.A. Martens, G.B. Marin, G.V. Baron, in: Proceedings of the 3rd Pacific Basin Conference, Kyongju, Republic of Korea, May 25-29, 2003, pp. 564-568.

[10] R.A. Ocakoglu, J.F.M. Denayer, G.B. Marin, J.A. Martens, G.V. Baron, J. Phys. Chem. B 107 (2003) 398-406.

[11] J.F. Denayer, A.R. Ocakoglu, W. Huybrechts, J.A. Martens, J.W. Thybaut, G.B. Marin, G.V. Baron, Chem. Commun. (2003) 1880-1881.

[12] J.F.M. Denayer, K. De Meyer, J.A. Martens, G.V. Baron, in: Proceedings of the 3rd Pacific Basin Conference, Kyongju, Republic of Korea, May 25-29, 2003, pp. 229-233.

[13] C.S. Laxmi Narasimhan, J.W. Thybaut, G.B. Marin, J.A. Martens, J.F. Denayer, G.V. Baron, J. Catal. 218 (2003) 135-147.

[14] W. Huybrechts, G. Vanbutsele, K.J. Houthoofd, F. Bertinchamps, C.S.L. Narasimhan, E.M. Gaigneaux, J.W. Thybaut, G.B. Marin, J.F.M. Denayer, G.V. Baron, P.A. Jacobs, J.A. Martens, Catal. Lett. 100 (2005) 235-242.

[15] C.S.L. Narasimhan, J.W. Thybaut, J.F. Denayer, G.V. Baron, P.A. Jacobs, J.A. Martens, G.B. Marin, Ind. Eng. Chem. Res. 46 (2007) 8710-8721.

[16] D. Dubbeldam, B. Smit, J. Phys. Chem. B 107 (2003) 12138-12152.

[17] D. Dubbeldam, S. Calero, T.L.M. Maesen, B. Smit, Angew. Chem. Int. Ed. 42 (2003) 3624-3626.

[18] C.N. Satterfield, J.R. Katzer, W.R. Vieth, Ind. Eng. Chem. Fundam. 10 (1971) 478-486.

[19] J.C. Cheng, T.F. Degnan, J.S. Beck, Y.Y. Huang, M. Kalyanaraman, J.A. Kowalski, C.A. Loehr, D.N. Mazzone, Stud. Surf. Sci. Catal. 121 (1999) 53-60.

[20] G. Sastre, C.R.A. Catlow, A. Corma, J. Phys. Chem. B 103 (1999) $5187-$ 5196.

[21] H. Du, D.H. Olson, J. Phys. Chem. B 106 (2002) 395-400.

[22] J. Weitkamp, M. Neuber, Stud. Surf. Sci. Catal. 60 (1991) 291-301.

[23] G.C. Smith, Catalytic Cracking of $n$-Alkanes and $n$-Alkylbenzenes over H-ZSM-5 Zeolite, Massachusetts Institute of Technology, Boston, 1993.

[24] T.L.M. Maesen, M. Schenk, T.J.H. Vlugt, J.P. de Jonge, B. Smit, J. Catal. 188 (1999) 403-412.

[25] G. Sastre, A. Chica, A. Corma, J. Catal. 195 (2000) 227-236.

[26] P. Raybaud, A. Patrigeon, H. Toulhoat, J. Catal. 197 (2001) 98-112.

[27] L. Domokos, L. Lefferts, K. Seshan, J.A. Lercher, J. Catal. 203 (2001) 351-361.

[28] V.M. Akhmedov, S.H. Al-Khowaiter, Catal. Rev. Sci. Eng. 49 (2007) 33139.

[29] S. Siffert, L. Gaillard, B.L. Su, J. Mol. Catal. A Chem. 153 (2000) 267279.

[30] A. Corma, V. Martinez-Soria, E. Schnoeveld, J. Catal. 192 (2000) 163 173.

[31] S.J. Miller, Catalytic dewaxing, US 4360419, 1982.

[32] J.G. Bendoraitis, A.W. Chester, F.G. Dwyer, W.E. Garwood, Stud. Surf. Sci. Catal. 28 (1986) 669-675.

[33] N.Y. Chen, T.F. Degnan Jr., B.P. Pelrine, R.F. Socha, Process and apparatus for catalytic dewaxing of paraffinic stocks and simultaneous removal of cracked products, US 4737263, 1988.

[34] I.E. Maxwell, W.H.J. Stork, Stud. Surf. Sci. Catal. 137 (2001) 747-819.

[35] D.J. O'Rear, B.K. Lok, Ind. Eng. Chem. Res. 30 (1991) 1100-1105.

[36] T.L.M. Maesen, B. Smit, E. Beerdsen, Dewaxing process using zeolites MTT and GON, US 2007029229, 2007.

[37] J. Weitkamp, ACS Symp. Ser. 20 (1975) 1-27.

[38] J. Weitkamp, Erdoel Kohle Erdgas Petrochem. 31 (1978) 13-22.

[39] T.L.M. Maesen, S. Calero, M. Schenk, B. Smit, J. Catal. 221 (2004) 241251.

[40] T.L.M. Maesen, M. Schenk, T.J.H. Vlugt, B. Smit, J. Catal. 203 (2001) 281-291.

[41] M. Schenk, B. Smit, T.J.H. Vlugt, T.L.M. Maesen, Angew. Chem. Int. Ed. 40 (2001) 736-739.
[42] S. Gopal, W. Zhang, P.G. Smirniotis, Ind. Eng. Chem. Res. 43 (2004) 2950-2956.

[43] S. Ernst, R. Kumar, J. Weitkamp, Catal. Today 3 (1988) 1-10.

[44] S. Ernst, J. Weitkamp, J.A. Martens, P.A. Jacobs, Appl. Catal. 48 (1989) 137-148.

[45] J.A.Z. Pieterse, S. Veefkind-Reyes, K. Seshan, J.A. Lercher, J. Phys. Chem. B 104 (2000) 5715-5723.

[46] R.M. Barrer, L.V.C. Rees, Trans. Faraday Soc. 57 (1961) 999-1007.

[47] R.M. Barrer, Zeolites and Clay Minerals as Sorbents and Molecular Sieves, Academic Press, San Francisco, 1978.

[48] R. Battino, Fluid Phase Equilib. 15 (1984) 231-240.

[49] E. Wilhelm, Develop. Appl. Solubility (2007) 3-18.

[50] W.O. Haag, R.M. Lago, P.B. Weisz, Faraday Discuss. Chem. Soc. 72 (1981) 317-330

[51] M.F.M. Post, J. Van Amstel, H.W. Kouwenhoven, in: Proc. 6th Int. Zeolite Conf., 1984, pp. 517-527.

[52] P. Voogd, H. Van Bekkum, Ind. Eng. Chem. Res. 30 (1991) 2123-2133.

[53] T.L.M. Maesen, E. Beerdsen, S. Calero, D. Dubbeldam, B. Smit, J. Catal. 237 (2006) 278-290.

[54] J. Wei, Ind. Eng. Chem. Res. 33 (1994) 2467-2472.

[55] J. Kaerger, D.M. Ruthven, Diffusion in Zeolites and Other Microporous Solids, Wiley, New York, 1992.

[56] R.L. June, A.T. Bell, D.N. Theodorou, J. Phys. Chem. 94 (1990) 15081516.

[57] D. Frenkel, B. Smit, Understanding Molecular Simulation: From Algorithms to Applications, Academic Press, San Diego, 2002.

[58] T.L. Hill, Theory of Physical Adsorption, Advances in Catalysis, vol. 4 , Academic Press, New York, 1952, pp. 211-258.

[59] D. Dubbeldam, S. Calero, T.J.H. Vlugt, R. Krishna, T.L.M. Maesen, E. Beerdsen, B. Smit, Phys. Rev. Lett. 93 (2004), 088302/1-02/4.

[60] D. Dubbeldam, S. Calero, T.J.H. Vlugt, R. Krishna, T.L.M. Maesen, B. Smit, J. Phys. Chem. B 108 (2004) 12301-12313.

[61] A.G. Bezus, A.V. Kiselev, A.A. Lopatkin, P.Q. Du, J. Chem. Soc. Faraday Trans. Mol. Chem. Phys. 74 (1978) 367-379.

[62] B. Liu, B. Smit, S. Calero, J. Phys. Chem. B 110 (2006) 20166-20171.

[63] R. Krishna, J.M. van Baten, Sep. Purif. Technol. 55 (2007) 246-255.

[64] A.L. Myers, AIChE J. 48 (2002) 145-160.

[65] A.L. Myers, Adsorption 9 (2003) 9-16.

[66] A.L. Myers, Colloids Surf. A Physicochem. Eng. Aspects 241 (2004) 914.

[67] J.P. Olivier, Stud. Surf. Sci. Catal. 149 (2004) 1-33.

[68] S.B. McCullen, P.T. Reischman, D.H. Olson, Zeolites 13 (1993) 640-644.

[69] F. Eder, Y. He, G. Nivarthy, J.A. Lercher, Rec. Trav. Chim. Pays-Bas 115 (1996) 531-535.

[70] F. Eder, J.A. Lercher, J. Phys. Chem. 100 (1996) 16460-16462.

[71] F. Eder, M. Stockenhuber, J.A. Lercher, Stud. Surf. Sci. Catal. 97 (1995) 495-500.

[72] F. Eder, Thermodynamics and Siting of Alkane Sorption in Molecular Sieves, University Twente, Enschede, 1996.

[73] F. Eder, M. Stockenhuber, J.A. Lercher, J. Phys. Chem. B 101 (1997) 5414-5419.

[74] F. Eder, J.A. Lercher, J. Phys. Chem. B 101 (1997) 1273-1278.

[75] F. Eder, J.A. Lercher, Zeolites 18 (1997) 75-81.

[76] J.A. Lercher, K. Seshan, Curr. Opin. Solid State Mater. Sci. 2 (1997) $57-$ 62.

[77] A. Bhan, R. Gounder, J. Macht, E. Iglesia, J. Catal. 253 (2008) 221-224.

[78] A.S. Coolidge, J. Am. Chem. Soc. 48 (1926) 1795-1814.

[79] J. Rouquerol, D. Avnir, C.W. Fairbridge, D.H. Everett, J.H. Haynes, N. Pernicone, J.D.F. Ramsay, K.S.W. Sing, K.K. Unger, Pure Appl. Chem. 66 (1994) 1739-1758.

[80] D.M. Ruthven, B.K. Kaul, Adsorption 4 (1998) 269-273.

[81] C.E. Ramachandran, B.A. Williams, J.A. van Bokhoven, J.T. Miller, J. Catal. 233 (2005) 100-108.

[82] P.B. Weisz, in: D.D. Eley, P.W. Selwood, P.B. Weisz (Eds.), Advan. Catalysis, vol. 13, Academic Press, New York and London, 1962, pp. 137-190.

[83] G.F. Froment, K.B. Bischoff, Chemical Reactor Analysis and Design, Wiley, New York, 1979.

[84] T.F. Degnan, C.R. Kennedy, AIChE J. 39 (1993) 607-614. 
[85] M. Temkin, Acta Physicochim. URSS 2 (1935) 313-316.

[86] D.W. Breck, Zeolite Molecular Sieves: Structure, Chemistry, and Use, Wiley, New York, 1974.

[87] I. Daems, R. Singh, G. Baron, J. Denayer, Chem. Commun. (2007) 13161318.

[88] S. Altwasser, C. Welker, Y. Traa, J. Weitkamp, Microporous Mesoporous Mater. 83 (2005) 345-356.

[89] L.B. Galperin, Appl. Catal. A Gen. 209 (2001) 257-268.

[90] Y. Hu, X. Wang, X. Guo, S. Li, S. Hu, H. Sun, B. Liang, Catal. Lett. 100 (2005) 59-65.
[91] N.Y. Chen, S.J. Lucki, E.B. Mower, J. Catal. 13 (1969) 331-334.

[92] M.S. Rigutto, R. Van Veen, L. Huve, Stud. Surf. Sci. Catal. 168 (2007) 855-913.

[93] E.G. Derouane, J. Catal. 100 (1986) 541-544.

[94] CRC Handbook of Chemistry and Physics, CRC Press/Taylor and Francis Group, Boca Raton, FL, 2006.

[95] C. Baerlocher, L.B. McCusker, D.H. Olson, Atlas of Zeolite Framework Types, Elsevier, Amsterdam, 2007.

[96] M.D. Foster, I. Rivin, M.M.J. Treacy, O. Delgado Friedrichs, Microporous Mesoporous Mater. 90 (2006) 32-38. 